\title{
O tempo do luto materno pelo filho que morreu na infância ${ }^{a}$
}

\section{The time of maternal bereavement after the child who died in childhood El tiempo del luto materno por el hijo que murió en la infancia}

\author{
Maria Augusta Rocha Bezerra ${ }^{1}$ (c) \\ Ruth Cardoso Rocha² \\ Cristianne Teixeira Carneiro ${ }^{2}$ (1) \\ Karla Nayalle de Souza Rocha ${ }^{3}$ (b) \\ Diogo Filipe Santos Moura ${ }^{4}$ (1) \\ Silvana Santiago da Rocha ${ }^{1}$ (D)
}

1. Universidade Federal do Piauí, Programa de Pós-Graduação em Enfermagem. Teresina, PI, Brasil.

2. Universidade Federal do Piauí, Departamento de Enfermagem. Floriano, $\mathrm{PI}$ Brasil.

3. Instituto Federal da Paraíba. Patos, PB, Brasil.

4. Instituto Federal do Piauí, Departamento de Filosofia. Floriano, PI, Brasil.

Autor correspondente:

Maria Augusta Rocha Bezerra.

E-mail: mariaaugusta@ufpi.edu.br

Recebido em 04/07/2021.

Aprovado em 07/10/2021.

DOI:https://doi.org/10.1590/2177-9465-EAN-2021-0264

\section{REsUmo}

Objetivo: desvelar o movimento existencial da mãe após a morte do filho por acidente doméstico na infância. Método: pesquisa embasada no referencial teórico-filosófico-metodológico da fenomenologia de Martin Heidegger, com dados coletados entre maio e junho de 2017, mediante entrevista fenomenológica com 10 mães cujos filhos morreram em decorrência de acidentes domésticos na infância. Resultados: da compreensão dos relatos, emergiram três temáticas: Lembrando o sofrimento profundo diante da morte do filho e os primeiros dias/meses sem ele; Revivendo a dor no presente, por meio da falta diária e das datas importantes e objetos/símbolos da criança; e Antecipando que a dor e a falta que sentem dos filhos nunca irão passar. Conclusão e implicações para a prática: o tempo não é preditor da elaboração do luto materno. Neste contexto, o vivido da mãe é composto por um conjunto de significados, que envolvem multiplicidade de fatores e geram importantes repercussões ao longo da vida. $\mathrm{Na}$ perspectiva para promoção do cuidado, emergem, assim, a necessidade de ampliar a compreensão e as ações de acolhimento à mãe enlutada, refletindo sobre a temporalidade como constituinte do enlutamento materno.

Palavras-chave: Acontecimentos que Mudam a Vida; Comportamento Materno; Criança; Luto; Morte.

\section{Abstract}

Objective: this study aimed at unveiling the existential movement of a mother after her child's death as a result of a home accident. Method: it was a research study based on the theoretical-philosophical-methodological framework of Martin Heidegger's phenomenology, whose data collection occurred between May and June 2017 through a phenomenological interview with 10 mothers whose children died as a result of a home accident. Results: from comprehension of the reports, three themes emerged: Remembering the deep suffering when facing the child's death and the first days/months without them; Reliving the pain in the present, through the child's daily absence and important dates and objects/symbols; and Anticipating that pain and yearning for the deceased will never disappear. Conclusion and implications for the practice: time is not a predictor for the elaboration of maternal bereavement. Thus, the maternal experience is composed of a set of meanings, which involve multiple factors and generate important repercussions throughout life. From the perspective of care promotion, the need to expand the understanding and the actions for welcoming bereaved mothers emerges, reflecting on temporality as part of maternal bereavement.

Keywords: Life-Changing Events; Maternal Behavior; Child; Bereavement; Death.

\section{RESUMEN}

Objetivo: develar el movimiento existencial de la madre tras la muerte del hijo a raíz de un accidente doméstico en la infancia. Método: investigación basada en el marco teórico-filosófico-metodológico de la fenomenología de Martin Heidegger, con datos recolectados entre mayo y junio de 2017, a través de entrevistas fenomenológicas con 10 madres cuyos hijos fallecieron como consecuencia de accidentes domésticos en la infancia. Resultados: de la comprensión de los relatos, surgieron tres temas: Recordar el profundo sufrimiento ante la muerte del niño y los primeros días/meses sin él; Revivir el dolor en el presente, a través de la ausencia diaria y las fechas y objetos/símbolos importantes del niño; y Anticipar que el dolor y la falta de sus hijos nunca desaparecerán. Conclusión e implicaciones para la práctica: el tiempo no prodice la elaboración del duelo materno. En este contexto, la experiencia de la madre se compone de un conjunto de significados, que involucran multiplicidad de factores y generan importantes repercusiones a lo largo de la vida. Desde la perspectiva de promover el cuidado, surge la necesidad de ampliar la comprensión y las acciones de acogida de la madre en duelo y reflexionar sobre la temporalidad como constituyente del duelo materno.

Palabras clave: Acontecimientos que Cambian la Vida; Conducta Materna; Niño; Duelo; Muerte. 


\section{INTRODUÇÃO}

Acidentes domésticos na infância são, geralmente, resultados da interação entre fatores ambientais e comportamentais, com quantidade significativa de casos passíveis de serem evitados ${ }^{1}$. Esse termo é conceituado como um evento não intencional, causador de danos físicos e emocionais, ocorrido no ambiente doméstico (moradia/espaço de convivência) e entorno. Optou-se por adotá-lo no estudo em conformidade com as determinações da Política Nacional de Redução da Morbimortalidade por Acidentes e Violências, por estar consagrado pelo uso, retirando-lhe, contudo, a conotação fortuita e casual que lhe pode ser imputada².

Os acidentes domésticos constituem a principal causa de morbidade e mortalidade entre crianças em todo o mundo ${ }^{3}$. Diferentemente das reduções globais na carga de doenças entre crianças por causas infecciosas, neonatais e associadas à nutrição, evidencia-se, globalmente, expressivo crescimento de mortes relacionadas a causas externas ${ }^{4}$. No contexto brasileiro, informações do Ministério da Saúde (MS), a partir da análise do Sistema de Informações sobre Mortalidade (SIM), mostram que, em 2019, ocorreram 2.926 óbitos de crianças menores de 10 anos em todo o país, em decorrência de causas externas, as quais incluem acidentes e violências. Destes, a maior parte foi decorrente de riscos acidentais associados à respiração (sufocação/estrangulamento em cama; obstrução de trato respiratório por alimentos/objetos; entre outros) - 764 (26,1\%); ou teve como causa afogamento e submersão acidentais $591(20,2 \%)$, acidentes que, em geral, ocorrem no domicílio ${ }^{5}$.

A morte de uma criança é um dos acontecimentos que mudam a vida, capaz de alterar o modo como os pais enlutados veem o mundo, a família e a si ${ }^{6}$, e pode ter consequências graves a longo prazo para a saúde física e psicológica ${ }^{7}$. Apesar disso, pouca atenção tem sido dada ao luto dos pais após a morte de um filho pequeno e dependente ${ }^{8}$. Para as mães, o luto, em geral, desencadeia cascata de respostas negativas e destrutivas, exigindo cuidado deliberado e extenso ${ }^{9}$. Neste contexto, destaca-se a natureza complexa e multifacetada das respostas adaptativas e complicadas do luto materno ${ }^{10}$, que aumentam as doenças mentais, como ansiedade e depressão, e contribuem para o uso de psicotrópicos ${ }^{11}$.

Tais distúrbios ainda são mais prevalentes entre pais cujos filhos morreram repentina e inesperadamente, como nos casos dos acidentes, apresentando carga especialmente elevada de sintomas relacionados ao luto ${ }^{8,12}$. Nessas situações, essa perda resulta em ampla gama de problemas de saúde mental, incluindo depressão grave, transtorno do estresse pós-traumático, luto complicado, além de insônia, problemas com o uso de álcool e dores psicossomáticas ${ }^{13}$.

Embora existam estudos acerca do luto parental, a questão do enlutamento envolve vivência temporal complexa ${ }^{14}$ que carece de investigação e aprofundamento ${ }^{15}$. Ao considerar que o tempo é uma dimensão importante nas respostas ao luto ${ }^{7}$ e a severidade das experiências de luto após a morte de uma criança pequena é potencialmente um subtipo distinto de luto, fomentase a necessidade da realização de pesquisas nessa área ${ }^{8,12}$.
O campo teórico de perda e luto está em evolução. No entanto, a maioria das teorias contemporâneas sobre o luto enfatiza que as mães enlutadas precisam se ajustar à nova realidade, em que o filho falecido já não está fisicamente presente. Esse reajuste pode ser visto como processo contínuo que leva de meses a anos para ser concluído, enquanto o luto, em si, pode nunca ser resolvido ${ }^{16}$. Isso está de acordo com a crescente literatura sobre vínculos contínuos, que sugere, em processos típicos de luto, que os relacionamentos com o falecido são remodelados e mantidos, em vez de abandonados, e desafiam o conceito dominante de rompimento de vínculos de luto na cultura ocidental recente ${ }^{17,18}$.

Compreender a experiência do luto de mães e o consequente impacto sobre o comportamento materno pode colaborar para que enfermeiros e demais profissionais da equipe multiprofissional em saúde atuem com empatia, considerando a subjetividade relacionada aos aspectos familiares, com vistas a contribuir para o atendimento integral, capaz de abranger o cuidado físico, emocional e espiritual ${ }^{19}$.

A partir do exposto, esta pesquisa se norteou pela questão: Como mães enlutadas se movimentam existencialmente após a morte de um filho por acidente doméstico na infância? Assim, objetivou-se desvelar o movimento existencial da mãe após a morte do filho por acidente doméstico na infância.

\section{MÉTODO}

Trata-se de estudo de natureza qualitativa, fundamentado no referencial teórico-filosófico-metodológico da fenomenologia de Martin Heidegger, na medida em que se buscou desenvolver olhar atentivo, para que o fenômeno velado se mostre por si mesmo. O método fenomenológico heideggeriano permite que o fenômeno seja desvelado, manifestando o sentido de ser e as estruturas fundamentais do Dasein. Tem o caráter de recusa de encobrimentos e distorções, uma vez que o fenômeno, na maioria das vezes, é mal compreendido ou insuficientemente interpretado, do ponto de vista ontológico ${ }^{20}$

O cenário da pesquisa foi a Atenção Primária à Saúde (APS) de um município da Região Nordeste do Brasil. Dados fornecidos pela Secretaria Municipal de Saúde apontam que a APS é composta por 24 Unidades Básicas de Saúde (UBS), sendo 14 localizadas na zona urbana e 10 na zona rural. Optou-se por incluir apenas as unidades da zona urbana, pela facilidade de acesso da pesquisadora.

O período para realização da etapa de campo foi entre maio e junho de 2017. As protagonistas do estudo foram mulheres cujos filhos morreram por acidentes domésticos na infância. Delimitaramse como critérios de inclusão: idade igual ou superior a 18 anos; e que o acidente doméstico tivesse ocorrido com a criança na faixa etária entre um dia de nascido e 12 anos. Determinou-se como critério de exclusão: mães que apresentassem alterações no processo cognitivo de pensamento.

Antes de iniciar as etapas de campo da pesquisa, observouse o cumprimento integral das questões éticas estabelecidas pelas Resoluções 466/2012 e 510/2016 do Conselho Nacional de Saúde. O estudo foi aprovado pelo Comitê de Ética em Pesquisa 
envolvendo seres Humanos da Universidade Federal do Piauí, em dezembro de 2016, conforme parecer $n$. o 1.872.403.

Para realização da coleta de dados, os Agentes Comunitários de Saúde (ACS) da APS colaboraram na indicação de possíveis participantes que se enquadravam nos critérios preestabelecidos para o estudo. Ao todo, 17 nomes foram listados, com a inclusão de 10 participantes. Enfatiza-se que não foi utilizado cálculo do tamanho da amostra, uma vez que ao desenvolver a etapa de campo concomitante ao movimento analítico, foi possível concluir a produção de dados quando os significados expressos nos relatos maternos mostraram suficiência de estruturas essenciais para compreensão do fenômeno sob investigação ${ }^{21}$. Todas as participantes que foram convidadas aceitaram colaborar com o estudo.

Nos encontros para produção de dados, utilizou-se da técnica de entrevista fenomenológica, mediada pela empatia e intersubjetividade. A questão norteadora que conduziu a entrevista foi: O que significa a morte de seu(ua) filho(a) por acidente doméstico?

Quanto ao local, sete participantes solicitaram que os encontros fossem realizados no próprio domicílio, duas em uma sala cedida na UBS do bairro, e uma na casa de um parente (local onde residia quando o acidente doméstico que vitimou a filha ocorreu). Realizaram-se de modo individual, audiogravadas, com autorização prévia e duração entre 30 e 90 minutos.

A analítica balizada no referencial metodológico heideggeriano envolveu dois momentos: a compreensão vaga e mediana e a compreensão hermenêutica. O primeiro momento foi realizado concomitantemente às entrevistas. Por meio dele, abordou-se a visão factual (ôntica) das participantes, em que foram enfatizados os significados por elas atribuídos ao fenômeno e, portanto, poderia estar impregnada de teorias tradicionais e opiniões sobre o ser, que constituem fontes de compreensão dominante ${ }^{20}$.

No segundo momento, buscou-se a compreensão hermenêutica, a qual projeta o ente preliminarmente dado no próprio ser, de modo a chegar ao conceito de estrutura. Deste modo, é possível ir além do conhecimento do que foi compreendido e elaborar as possibilidades projetadas na compreensão. Trata-se do trabalho de interpretação hermenêutica, retirando o encobrimento provocado pelas falas que se ligaram fortemente a quem ouviu e produz o velamento dos sentidos ${ }^{20-22}$.

Para preservar o anonimato das participantes, estas foram identificadas com código composto pela letra $\mathrm{M}$, seguida do número arábico correspondente à ordem de realização das entrevistas (M1, M2, M3... M10). O nome do filho que morreu em decorrência de acidente doméstico foi substituído pela letra $F$, também seguida do número arábico correspondente à ordem de realização das entrevistas (F1, F2, F3... F10).

\section{RESULTADOS}

Compuseram os resultados deste estudo os dados advindos da análise das entrevistas de 10 mães cujos filhos morreram em decorrência de acidentes domésticos, com idades que variavam entre 28 e 82 anos, em maioria, casadas ou em união estável
(06). A maior parte (04) referiu ter como ocupação a realização de atividades no lar. $O$ tempo decorrido do acidente variou entre um e 53 anos. Os acidentes domésticos que vitimaram as crianças foram: envenenamento (03), acidentes por choque elétrico (03), afogamentos (03) e engasgo (01). Quanto ao sexo das vítimas, seis eram meninos e quatro meninas, com idades variando entre um e 11 anos.

A reunião dos recortes extraídos dos depoimentos expostos pela linguagem oral das participantes e transcritos in verbatim permitiu a construção de três unidades de significação que possibilitaram a interpretação dos sentidos do ser-aí-mãe para alcançar o movimento existencial que é a temporalidade após a morte do filho, a saber: Lembrando o sofrimento profundo diante da morte do filho e os primeiros dias/meses sem ele; Revivendo a dor no presente, através da falta diária e das datas importantes e objetos/símbolos da criança; e Antecipando que a dor e a falta que sentem dos filhos nunca irão passar.

\section{Lembrando o sofrimento profundo diante da morte do filho e os primeiros dias/meses sem ele}

As mães explicitaram que, nos primeiros dias após a morte do filho, depararam-se com a nova realidade de vida, instituída pela falta da criança, caracterizada pela impossibilidade de ver e/ou ouvir o filho e descrita como impactante e limitadora das atividades diárias. Apesar da ausência, continuavam sentindo a presença do filho, às vezes, vendo-o, ouvindo-o e/ou sonhando com ele. Desencadearam-se, muitas vezes, o isolamento materno, a inapetência, a insônia e, em todos os casos, a necessidade de se readaptar, exigindo tempo diferenciado para cada mãe conseguir diluir o sofrimento e elaborar a morte do filho. Sobre esse aspecto, enfatiza-se que o tempo cronológico não foi preditor da elaboração do luto.

Essa compreensão foi possível pelo fato de que inexistiu qualquer hierarquização de correspondência entre os anos de falecimento dos filhos e resolução mais efetiva do luto. Ou seja, mãe cujo filho morreu há 27 anos expressou sofrimento como mães de filho falecido há dez ou apenas um ano. Mãe cujo filho havia falecido há um ano (M2) demonstrou resolução mais efetiva do luto comparativamente àquela em que o filho havia morrido há 10 anos (M10) ou 27 anos (M5), por exemplo.

Nesse sentido, as mães descreveram distúrbios mentais, como depressão e sintomatologia relativa ao luto complicado, independentemente do tempo transcorrido após a morte do filho e, inclusive, ideação suicida, porém, afirmaram que precisaram suportar por causa dos outros filhos. Expressaram que os primeiros dias e meses e o primeiro ano após a morte do filho foram mais difíceis, em especial pela proximidade com a ocorrência. Muitas abandonaram a residência que moravam e local onde, na maior parte dos casos, o acidente doméstico ocorreu, por não suportar as lembranças e a dor gerada pelo cenário e pelas rotinas e que as faziam sentir a presença do filho em todo o lugar. A seguir, para melhor compreensão das transformações sucedidas no passado em decorrência da morte do filho, foram extraídos trechos que retrataram esse período. 
... aí quando foi de manhã [no dia posterior ao sepultamento do filho] que eu acordei foi que a ficha caiu, de não ver mais ele [F1], saber [...] que não ia ter mais ele me chamando de mãe [...] O primeiro ano é muito difícil, porque são muitas datas. Era a gente deixar de fazer muita comida que ele gostava, por muito tempo, porque eu não conseguia fazer [...] (emocionada) (silêncio) (M1).

[...] assim quando ela [F3] morreu, eu sentia a presença dela. Eu não vou dizer que eu a via [F3] que eu não via, mas eu via em sonho [...] a gente quando é novo é besta. Aí, eu disse que queria morrer também, queria ir com ela [...] (M3).

[quando ele morreu] quase fico louca (chora) [...] eu não conversava [...] (faz uma grande pausa, chorando), eu não comia (chora copiosamente) ... fui indo, aí botei a cabeça no lugar de volta... (silêncio, chora) [...](M5).

Quando ela morreu, eu saí da casa [...] eu larguei a casa porque eu não aguentava ver aquele lugar onde ela tinha morrido [...] eu fiquei (chora) [...] eu fiz ele [ex-esposo] sair [...] nós saímos da casa! (M9).

\section{Revivendo a dor no presente, por meio da falta diária e das datas importantes e objetos/símbolos da criança}

No presente, as mães destacaram que as memórias dos filhos são revividas, bem como a dor e o sofrimento intenso, em datas importantes, como no aniversário de vida, no aniversário de morte, no dia das crianças, no dia das mães, no dia de finados, ou em momentos típicos da infância, como a ida a parques de diversão. Revelaram, ainda, o cuidado dispensado ao filho falecido nessas ocasiões, por meio de rituais, como a visita ao túmulo do filho no cemitério, o velar do corpo ausente e procedimentos que objetivam amenizar o sofrimento e ajudá-las a lidar melhor com a lacuna deixada pela criança.

Também expuseram que, independentemente desses momentos especiais, a falta do filho é sentida diariamente e que a lembrança e a dor são permanentes, apesar de não serem mais limitadoras, uma vez que elas já são capazes de fazer as atividades diárias. Destacaram que a morte/perda do filho não cessa de fazer-se lembrada. No entanto, compreenderam que mesmo não sendo capazes de superar a morte do filho, vão se acostumando com a nova realidade e levando a vida. Ademais, objetos/símbolos do filho falecido também geraram sofrimento intenso nas mães, fazendo as participantes rememorarem a época em que o filho estava vivo, o acidente doméstico e o momento da morte deste. Relataram não quererem/conseguirem se desfazer dos objetos/coisas do filho, apesar destes evocarem as memórias do dia a dia com a criança falecida.

Aí, é o aniversário dele, é o dia das crianças, é o dia de parquinho vir para a cidade e a gente lembrar que levava. Então, os anos vão passando, não tem mais o ano passado para você lembrar, mas tem aquela data [...] se tivesse aqui, hoje era desse jeito, era daquele jeito, então, são datas que a gente vai no cemitério, a gente faz a visita, a gente chora, a gente lembra o momento do enterro, a gente volta tudo, volta [...] é como se fosse uma fita cassete que você bota e volta de novo... e vai tudo de novo acontecendo [...] (M1).

Está com mais de 50 anos, mais ainda hoje eu lembro dele $[\ldots](\mathrm{M} 4)$.

[...] ainda hoje eu tenho dois brinquedos dele: um carrinho daqueles pequenininho de fórmula 1 e um ovinho de páscoa, de brinquedo, de plástico [...] (M7).

\section{Antecipando que a dor e a falta que sentem dos filhos nunca irão passar}

Com relação ao futuro, as participantes fizeram, ainda, projeções com o filho falecido, aludindo que "se meu filho tivesse vivo", seria desse ou daquele modo, ao mesmo tempo em que o veem como na época em que faleceu, falando, por vezes, no tempo verbal passado e, em outras, no presente. Declararam que a dor e a falta desencadeadas pela morte nunca irão passar ou não sabem quando o sofrimento intenso irá terminar e referiram não ter perspectivas quanto ao futuro.

se ele tivesse vivo, ia fazer 14 anos [...] [tinha] uma vida toda pela frente [...] sempre que você vai na rua comprar alguma coisa, você olha para uma roupinha, de menino de 14 anos, você olha [...] já servia nele. Aí, vê uma roupinha pequena [...] oh ele usava assim. O tempo passa, mas é muito presente [...] a verdade que não, não supera [a morte do filho] [...] (M1).

... se ele tivesse vivo, ele tinha hoje 10 anos [...] é o filho homem que eu sonhei ter (M7).

[...] eu não vejo futuro. Para mim, o tempo parou [...] parou de vez [...] (M8).

Aí, eram oito mulheres e três homens. E só tenho sete "mulherzinhas", uns casados, outros se amigaram, moram com os maridos [...] ela não pôde fazer nada disso (M9).

Se ele tivesse vivo, ele já tinha 10 anos já, já estava grande, estava aí brincando. Já passou 10 anos, já era para gente está falando normal, não é?! Mas, eu não consigo falar (chora) [...] eu não sei quando essa dor vai passar (M10).

\section{DISCUSSÃO}

Para desvelar o movimento existencial da mãe após a morte do filho por acidente doméstico na infância, é preciso conhecer os modos de ser-no-mundo, o Dasein que diz respeito ao homem lançado em um mundo que o habita e é capaz, também, de 
questionar a própria realidade e a si. O ser-aí-mãe-cujo-filhomorreu-em-decorrência-de-acidente-doméstico-na-infância, ao expressar os significados do seu vivido, os quais compuseram o fio condutor que permitiu avançar para essa análise hermenêutica, desvelou-se como si-mesmo (impessoalmente ou propriamente), enquanto aquilo que em todo caminho histórico de seu Dasein se manteve constantemente como ele, justamente no modo do ser-no-mundo, do poder-ser-no-mundo ${ }^{23}$.

É no mundo vivido ou como ser-no-mundo que as determinações do ser da presença devem ser vistas e compreendidas ${ }^{20}$. Nesta perspectiva, ao fazer referência ao mundo do ser-aí-mãe, estarse-á direcionando-se ao seu vivido e a sua mundaneidade enquanto característica existencial, em que se fundamentam as várias maneiras específicas de viver que, nesse contexto, dizem respeito ao cotidiano, envolvendo comportamentos, hábitos, afazeres, entre outros aspectos ${ }^{20}$.

Em seu mundo, marcado pela morte do filho, a mãe sente a falta deste no passado, no presente e já compreende e antecipa que sentirá no futuro. O ser-aí-mãe junta, respectivamente, o passado (vigor-de-ter-sido), o presente (atualidade) e o futuro (porvir) de uma forma ou de outra, no sentido de aproximálos e, assim, formar e estabelecer a respectiva estrutura de tempo, para, desse modo, temporalizar a morada ${ }^{23}$. Embora se tenha explicitado cada tempo separadamente, no horizonte da temporalidade, essa separação não é possível, pois o Dasein não vive o tempo, ele é tempo ${ }^{20}$. Assim, a vida e a morte estão dadas para o ser-no-mundo, em temporalidade, e tratadas não enquanto partes de um existir, mas como condição intrínseca do $\operatorname{ser}^{24}$.

Ao conduzir as ações o Dasein determina se a temporalidade é própria ou imprópria. O cerne da temporalidade imprópria é o tempo como sequência de instantes, concebido para fora das atividades e propósitos do Dasein. Os conceitos de passado, presente e futuro emergem da compreensão imprópria do tempo. Vigor-de-ter-sido, atualidade e povir, denominados por Heidegger de ekstases, mostram os caracteres fenomenais da temporalidade originária e própria ${ }^{20-25}$. Descreve-se a temporalidade como a articulação entre o porvir e o vigor-de-ter-sido, que se atualiza na realização das possibilidades de ser do Dasein em seu projetar-se $\mathrm{s}^{20,23,26}$.

Assim, o passado corresponde ao retorno ao vivido, o presente à ocupação com as coisas do mundo e o futuro às possibilidades de ser. O ser-aí-mãe, ao comentar sobre seu vivido, mostrou-se presa ao passado, ao vigor-de-ter-sido. No discurso das mães, visualiza-se que o tempo de estar enlutado não é delimitado pelo passar dos dias. Ao contrário, nota-se que o tempo cronológico não apaga as lembranças, pois a presença do filho continua viva em seu existir-no-mundo ${ }^{27}$.

Isso se deve porque lançado na facticidade de ser-semo-filho, o ser-aí-mãe não perde seu status social de ser mãe, como no caso da esposa cujo marido morreu e passa, então, a ser viúva, ou do filho que perdeu sua mãe e passa a ser órfão. O ser-aí-mãe-de-um-filho-vivo é agora o ser-aí-mãe-cujo-filhomorreu-em-decorrência-de-acidente-doméstico-na-infância em busca do seu novo lugar. Para o ser-aí-mãe, não foi apenas o filho que morreu, mas também o modo de existir que se mostrava apenas na relação com ele ${ }^{28}$. Essa presença sentida é o resultado de uma história acumulada de encontros e interações com filho que deixou rastros no corpo e no espaço vivido. Assim, no decorrer da partilha de suas vidas, mãe e filho se tornaram parte de uma esfera intercorpórea com o estilo específico de falar, sorrir, caminhar juntos, entre outros compartilhamentos. Luto também significa separação dessa intercorporalidade ${ }^{18}$.

Nesse contexto, o passado tem primazia e influência sobre presente e futuro. $\mathrm{Na}$ atualidade, mesmo o filho não estando presente fisicamente, uma nova forma da mãe se relacionar com ele emerge: o modus de presença da ausência. $O$ filho que morreu pode tornar-se mais presente para a mãe enlutada em sua ausência do que ele jamais o foi enquanto vivo ${ }^{23}$. É, por esse motivo, que, mesmo não estando presente, o ser-aí-mãe podia senti-lo de modo até a conseguir vê-lo e escutá-lo e/ou com ele sonhar. Assim, ainda que não estivesse fisicamente presente, esse filho se mantém no existir materno enquanto presença.

No luto, a mãe experimenta ambiguidade fundamental entre a presença e a ausência do filho falecido, entre o presente e o passado, que, na verdade, apresentam-se como duas formas conflitantes de presente, a saber: a realidade contínua da vida cotidiana; e a presença persistente do ente querido. A temporalidade do luto pode ser descrita como a separação dessas duas formas de tempo, uma fluindo e outra presa, que se tornam, cada vez mais, dessincronizadas. No primeiro caso, o filho amado está morto e o mundo segue em frente, e, no segundo, ele ainda está vividamente presente. Em certo sentido, ele não está mais sujeito à progressão do tempo e permanece o mesmo. Ainda que passem os anos, as memórias dele podem ser tão vivas quanto eram no início ${ }^{18}$.

Como a mãe não pode mais se ocupar e cuidar do filho, nos modos de ser de quando ele estava vivo, ela buscou ocupar-se dele no funeral, no enterro e, ainda, ocupa-se nas cerimônias destinadas aos que morreram (dia de finados e outras datas que julga merecedoras de culto). Junto com o filho, na homenagem do culto, o ser-aí-mãe é e está com ele, no modo de uma preocupação reverencia ${ }^{20}$. A função desses rituais, muitas vezes balizados pela religião e/ou espiritualidade, é estabelecer e confirmar gradualmente a nova ordem, e não menos importante, demarcar claramente os domínios da vida e da morte novamente ${ }^{18}$.

No confronto com a perda do filho, as mães encontram experiências especiais de natureza transcendente, que as ajudam a se manterem conectadas ao filho após a morte dele. Neste contexto, a espiritualidade é significativa na perspectiva que, de algum modo, oferece amparo diante da realidade existencialmente perturbadora da perda. Assim, a dimensão espiritual faz parte do cuidado ao luto materno, e os profissionais de saúde devem estar cientes de sua relevância e considerar a oferta de cuidado compassivo adequado ${ }^{29}$

Em decorrência do luto, a mãe sentiu sintomas físicos e mentais: afirmou que "não consegue comer" (inapetência), "não 
consegue dormir" (insônia), "quase enlouquece", "deprime-se". No entanto, tal sintomatologia não pode ser compreendida apenas do ponto de vista do paradigma biomédico positivista, como geralmente é feito. Esses sintomas revelam muito mais do que uma somatização ou um traço característico do luto materno.

É preciso compreender que o que surge na aparência do ser-aí-mãe, na verdade, vela o sofrimento causado pela falta do filho, que distorce e o manifesta como sintomatologia. Este encobrimento em forma de distorção é o mais frequente e o que apresenta maiores riscos, pois as possibilidades de engano e desorientação são particularmente severas e persistentes ${ }^{20}$.

Erros não intencionais são frequentemente cometidos por médicos e outros profissionais da saúde, devido ao desconhecimento sobre o impacto psicológico da morte infantil ${ }^{30}$. Por esse motivo, existe recorrente psicologização e psiquiatrização na gestão do sofrimento de mães enlutadas, bem como evidente medicalização que perpassa, cada vez mais, o luto ${ }^{31}$. Apesar de se compreender que o uso de medicamentos psicotrópicos pode ser interpretado como um meio de lidar com problemas de saúde mental subjacentes após o evento traumático da morte de uma criança, também é possível que essa medicação seja usada para tratar reações normais de luto, e não apenas luto complicado ${ }^{32}$.

Ainda preso ao passado, o ser-aí-mãe abandona a residência que morava e local onde, na maior parte dos casos, o acidente doméstico ocorreu, por não suportar as lembranças e a dor gerada pelo cenário e pelas rotinas e que o faziam sentir a presença do filho em todo o lugar. O desejo de deixar aquele ambiente que, para o ser-aí-mãe gerou tamanho sofrimento, implica, mais do que abandonar ou se distanciar do espaço físico e concreto, significa ir em busca de uma nova morada que lhe devolva a segurança e familiaridade perdidas.

Essa atitude ôntica de deixar a casa, na verdade, revela uma outra característica ontológico-existencial fundamental e genuína do ser-aí: o espacializar, que é o sentir-se próximo ou afastado de algo ou alguém. O Dasein pode sentir-se muito próximo a alguém ao pensar nele, e muito afastado de uma pessoa ou de um objeto ainda que esteja ao seu lado. Deste modo, através do seu corpo, gestos e, até mesmo, pensamentos, o ser-aí-mãe pode se aproximar ou se afastar dos outros, pode achar ou não seu lugar no ambiente. Todas essas maneiras ônticas têm origem no ontológico espacializar. Assim, é possível afirmar que a mudança topográfica materna se origina desse existencial ${ }^{33}$.

Desamparado e tentando escapar dessa vivência singular, estranha e que o colocou fora da proteção da cotidianidade com a qual estava habituado, o ser-aí-mãe foge desse ambiente que era parte do seu espaço e constituía, assim, o seu mundo ${ }^{20}$. Com a morte do filho, o ambiente doméstico já não é mais familiar, pois o ser-aí-mãe perdeu parte dos referenciais com os quais se orientava. Esse querer deixar/abandonar a casa onde convivia com o filho que morreu, não deve ser compreendido como distância, que é uma determinação categorial dos entes destituídos do modo de ser da presença, mas como dis- tanciamento, que deve ser mantido como existencial relativo à espacialidade do Dasein no mundo.

Nesse sentido, esse dis-tanciar da presença não deve ser estimado em termos geométrico-espaciais, mas em termos cotidianos da temporalidade. Ao querer deixar/abandonar a casa, o ser-aí-mãe, na verdade, deseja "fazer a distância desaparecer", a distância desse novo cotidiano em relação ao anterior, no qual o filho estava presente ${ }^{25}$. Deixando a casa, o ser-aí-mãe tenta se dis-tanciar do filho perdido em decorrência do acidente doméstico naquele ambiente e se aproximar do filho vivo, ao pensar nele sem as lembranças da tragédia que o ambiente a fazem rememorar ${ }^{33}$.

A separação gerada pela morte do filho também pertence ao mundo compartilhado. Viver junto com ele criou uma esfera de hábitos e práticas comuns (compartilhar atividades de lazer, cozinhar, cuidar da higiene, entre outras atividades habituais que implicavam o relacionamento com o filho falecido e que agora perderam significado) e, com isso, um significado consensual de objetos familiares, lugares e recordações. A mãe enlutada, no entanto, é arrancada deste mundo compartilhado. Agora, o ambiente familiar se transforma em um lugar de dolorosa ausência, vazio e até repelente alienação ${ }^{18}$.

No entanto, ainda que o ser-aí-mãe mude de ambiente, as memórias do filho permanecem diariamente e são intensificadas no encontro com seus objetos, que não são apenas coisas materiais, mas repletas de significado e capazes de tornar presentes as experiências compartilhadas com o filho há certo tempo. O modo de presença do filho que morreu, assume, assim, o modus da lembrança de algo acontecido em determinado momento, através de objetos pessoais ${ }^{23,34}$.

Nessa perspectiva, as recordações estão inseridas no dia a dia do ser-aí-mãe. A lembrança do acontecido (tanto a convivência com o filho, como o acidente doméstico e sua morte) é determinante do presente e futuro. Para o ser-aí-mãe, essas recordações adquirem o sentido de manutenção da existência do filho na própria existência. Mesmo não sendo capaz de compartilhar o mesmo mundo com o filho, o seu mundo de mãe, constituído de roupas que o filho usava, fotos emolduradas na parede, brinquedos e lembranças remanescentes da relação vivida, admite a copresença do filho sob esse novo status, o modus da lembrança ${ }^{23}$. A busca na memória das lembranças com o filho ajuda as mães a encontrarem uma maneira de continuar seu vínculo com a criança na nova realidade ${ }^{16}$.

Os objetos descritos, que ativam as lembranças, denominados de objetos transicionais, fornecem segurança e conexão simbólica com outras pessoas valiosas, quando separados delas. Pais enlutados costumam guardar, cuidar e visitar objetos salvos de seus filhos falecidos e, por isso, constituem aspectos-chave do luto. Nesta perspectiva, faz-se necessário compreender os potenciais usos terapêuticos de objetos transicionais na promoção do ajustamento ao luto ${ }^{35}$, os quais têm sido recomendados por pesquisas como uma maneira concreta e física para mães enlutadas se sentirem mais próximas de seus filhos falecidos e manter conexão com eles ${ }^{36,37}$. 
Para o ser-aí-mãe, a morte do filho se revelou como um fenômeno que agora permeia o dia a dia. No vigor-de-ter-sidomãe-desse-filho-vivo, mesmo com a morte, oscila em falar dele, ora no passado, ora no presente, ora no futuro, quando faz projeções, afirmando que "se meu filho estivesse vivo", seria dessa ou daquela maneira ou o visualizando, na atualidade, na idade que ele poderia ter, se não tivesse morrido.

A morte de um filho, em especial na infância, significa que seu futuro (porvir) foi interrompido. Isso diz respeito não apenas ao futuro e ao poder-ser do filho falecido, mas também ao da mãe. As projeções existenciais são suspensas de forma brusca. Por não aceitar que o poder-ser do filho e seu poder-ser como mãe desse filho vivo não mais existam, o ser-aí-mãe se imagina nesse futuro com ele $^{23}$.

Fazer projeções com o futuro da criança permite às mães se reconectarem com o filho falecido. Ainda que se mostrem frustradas e tristes porque o futuro de seu filho foi interrompido e elas não puderam testemunhar seu filho envelhecer, para essas mães, sonhar com o futuro de seu filho falecido trouxe um conforto considerável ${ }^{38}$. Esses resultados são consistentes com novos modelos de luto, que possuem foco no desenvolvimento e na manutenção de conexões com o falecido, na forma de vínculos contínuos, encontrando significado na perda e viver com ela, em vez de se recuperar dela ${ }^{15,39}$

Ao passo que pensa em um futuro impossível ao lado do filho, as mães se mostram presas a um tempo congelado ou atemporal e cativadas por um passado duradouro, e, por esse motivo, abstêm-se de fazer planos ou projetos e de tomar parte na vida contínua de outras pessoas. Em vez disso, elas preservam e valorizam os memoriais dos filhos, brinquedos, roupas ou outros pertences, "presentificando" assim a criança falecida ${ }^{18}$.

No movimento existencial, o ser-aí-mãe conecta, ainda que de modo inautêntico, vigor-de-ter-sido, atualidade e porvir, com um objetivo principal: manter vínculo com o filho falecido. As mães não querem deixar de falar dos filhos, ou parar de lembrar dos momentos que tiveram ao lado dele. Elas desejam ser ouvidas em sua dor, falar da vida que tinham antes do acidente que vitimou a criança, tocar os objetos que a ela pertenciam e que ajudam o passado a retornar. Não querem nem podem deixar o passado para traz. Esses dados convergem com a síntese teórica atual que mostra a necessidade de intervenções no enlutamento materno, com enfoque na natureza contínua do luto, destacando-se aquelas projetadas para guardar lembranças e relembrar memórias e para o reconhecimento contínuo da criança no vivido materno ${ }^{16}$.

\section{CONCLUSÕES E IMPLICAÇÕES PARA A PRÁTICA}

O adentrar no mundo das mães cujos filhos morreram em decorrência de acidentes domésticos possibilitou não apenas vislumbrar o ser humano fragilizado, mas compreender este ser em seu movimento existencial. Diante destas condições, desvelou-se que, embora a dor e falta da criança sejam mais intensamente sentidas em datas especiais, a perda do filho é sentida diariamente, permitindo concluir que a lembrança e a dor são permanentes, embora não mais limitadoras das atividades maternas no presente. Ainda no horizonte da temporalidade, outra faceta desvelada diz respeito ao futuro da mãe, em que as possibilidades de ser envolvem projeções com o filho falecido e a imaginação de um futuro impossível ao seu lado. Essa condição reforça que o processo transformador do luto deve ser analisado como ajuste gradual à perda, que permita a reintegração das realidades conflitantes: a morte do filho e a presença permanente dele.

Assim, é possível planejar um cuidado norteado pelo vivido/ vivência da mãe, voltado para ações que vão além das questões técnicas direcionadas ao sofrimento relativo ao enlutamento materno. Neste sentido, o cuidado não estará voltado para uma queixa somática ou sintoma identificado relativo ao luto complicado, mas será norteado pela movimentação específica do acontecer da mãe do seu nascimento até a morte. Essas reflexões permitem aos profissionais adquirirem visão ampliada acerca do fenômeno do enlutamento materno em decorrência de acidente doméstico, no contexto da infância, olhar construído a partir da percepção das mães que perderam suas crianças.

Por fim, é preciso considerar que, embora o processo de luto materno possa apresentar significativa variabilidade, no que diz respeito à duração e aos modos individuais de enfrentamento, a manutenção dos laços afetivos com o filho não está sujeita ao tempo linear. A mãe deseja manter o filho falecido presente permanentemente em seu vivido. Qualquer estratégia terapêutica de ajustamento ao luto deve, portanto, considerar essa premissa.

O estudo apresentou como limitação o emprego de somente uma estratégia de produção de dados, já que a associação de diferentes técnicas, especialmente grupais, poderia proporcionar dados do discurso coletivo aos achados da investigação. Ressaltase, também, que esse relato fenomenológico do luto materno tentou apreender elementos essenciais, que correspondem, em especial, à tradição cultural brasileira e, portanto, não abrangem formas de luto em outras culturas com igual concisão.

\section{CONTRIBUIÇÕES DOS AUTORES}

Desenho do estudo. Maria Augusta Rocha Bezerra. Silvana Santiago da Rocha. Cristianne Teixeira Carneiro. Karla Nayalle de Sousa Rocha. Diogo Filipe Santos Moura.

Coleta ou produção dos dados. Maria Augusta Rocha Bezerra. Cristianne Teixeira Carneiro. Karla Nayalle de Sousa Rocha. Diogo Filipe Santos Moura.

Análise de dados. Maria Augusta Rocha Bezerra. Cristianne Teixeira Carneiro. Karla Nayalle de Sousa Rocha. Diogo Filipe Santos Moura

Interpretação dos resultados. Maria Augusta Rocha Bezerra. Silvana Santiago da Rocha. Ruth Cardoso Rocha.

Redação e revisão crítica do manuscrito. Maria Augusta Rocha Bezerra. Silvana Santiago da Rocha. Ruth Cardoso Rocha. Cristianne Teixeira Carneiro. Karla Nayalle de Sousa Rocha. Diogo Filipe Santos Moura. 
Aprovação da versão final do artigo. Maria Augusta Rocha Bezerra. Silvana Santiago da Rocha. Ruth Cardoso Rocha. Cristianne Teixeira Carneiro. Karla Nayalle de Sousa Rocha. Diogo Filipe Santos Moura.

Responsabilidade por todos os aspectos do conteúdo e a integridade do artigo publicado. Maria Augusta Rocha Bezerra. Silvana Santiago da Rocha. Ruth Cardoso Rocha. Cristianne Teixeira Carneiro. Karla Nayalle de Sousa Rocha. Diogo Filipe Santos Moura.

\section{EDITOR ASSOCIADO}

\section{Eliane Tatsch Neves (D)}

\section{EDITOR CIENTÍFICO}

\author{
Ivone Evangelista Cabral (i)
}

\section{REFERÊNCIAS}

1. Piffer S, D'Alpaos A, Demonti S, Rampon C. Home accidents in the first two years of life and the relationship with parent characteristics. Nur Primary Care [Internet]. 2020; [citado 2003 set 10];4(6):1-6. Disponível em: https://scivisionpub.com/pdfs/home-accidents-in-the-first-two-yearsof-life-and-the-relationship-with-parent-characteristics-an-informationflowbased-study-1416.pdf

2. Portaria MS/GM no 737 , de 16 de maio de 2001 (BR). Política de redução da morbimortalidade por acidentes e violências. Diário Oficial da União [periódico na internet], Brasília (DF), 18 maio 2001 [citado 2021 ago 22]. Disponível em: https://bvsms.saude.gov.br/bvs/publicacoes/ saude_crianca_crescimento_desenvolvimento.pdf

3. Ahmed A, Abubakar S, Farouk Z, Gadanya M, Jimoh ML. Prevalence and pattern of unintentional domestic accidents and trauma amongst children attending public hospitals in Kano, Nigeria. Sahel Med J. 2018;21(1):6. http://dx.doi.org/10.4103/1118-8561.232787.

4. Kassebaum N, Kyu HH, Zoeckler L, Olsen HE, Thomas K, Pinho C et al. Child and adolescent health from 1990 to 2015 : findings from the global burden of diseases, injuries, and risk factors 2015 study. JAMA Pediatr. 2017;171(6):573. http://dx.doi.org/10.1001/jamapediatrics.2017.0250. PMid:28384795.

5. Ministério da Saúde (BR), Departamento de Informática do Sistema Único de Saúde. Informações de saúde: estatísticas de mortalidade: óbitos por ocorrência segundo causas externas do Brasil [Internet] Brasília: Ministério da Saúde; 2019 [citado 2021 abr 20]. Disponível em: http://tabnet.datasus.gov.br/cgi/deftohtm.exe?sim/cnv/ext10uf.def

6. Wonch Hill P, Cacciatore J, Shreffler KM, Pritchard KM. The loss of self: The effect of miscarriage, stillbirth, and child death on maternal self-esteem. Death Stud. 2017;41(4):226-35. http://dx.doi.org/10.108 0/07481187.2016.1261204. PMid:27854184.

7. Tseng YF, Cheng HR, Chen YP, Yang SF, Cheng PT. Grief reactions of couples to perinatal loss: a one-year prospective follow-up. J Clin Nurs. 2017;26(23-24):5133-42. http://dx.doi.org/10.1111/jocn.14059. PMid:28880461.

8. Morris S, Fletcher K, Goldstein R. The grief of parents after the death of a young child. J Clin Psychol Med Settings. 2019;26(3):321-38. http:// dx.doi.org/10.1007/s10880-018-9590-7. PMid:30488260.

9. Meisenhelder JB. Maternal grief: analysis and therapeutic recommendations. BMJ Support Palliat Care. 2021;11(1):101-6. http://dx.doi.org/10.1136/ bmjspcare-2020-002673. PMid:33239325.

10. Gerrish NJ, Bailey S. Maternal grief: a qualitative investigation of mothers' responses to the death of a child from cancer. Omega. 2020;81(2):197241. http://dx.doi.org/10.1177/0030222818762190. PMid:29570031.

11. Wall-Wieler E, Roos LL, Bolton J. Duration of maternal mental health-related outcomes after an infant's death: a retrospective matched cohort study using linkable administrative data. Depress Anxiety. 2018;35(4):305-12 http://dx.doi.org/10.1002/da.22729. PMid:29451948.

12. Boelen PA, Smid GE. Disturbed grief: prolonged grief disorder and persistent complex bereavement disorder. BMJ.2017;357:j2016. http:// dx.doi.org/10.1136/bmj.j2016. PMid:28522468.

13. Huh HJ, Huh S, Lee SH, Chae JH. Unresolved bereavement and other mental health problems in parents of the sewol ferry accident after 18 months. Psychiatry Investig. 2017;14(3):231-9. http://dx.doi.org/10.4306/ pi.2017.14.3.231. PMid:28539941.

14. Lima S, Fortim I. A escrita como recurso terapêutico no luto materno de natimortos. Rev Latinoam Psicopatol Fundam. 2015;18(4):771-88. http://dx.doi.org/10.1590/1415-4714.2015v18n4p771.12.

15. Snaman J, Morris SE, Rosenberg AR, Holder R, Baker J, Wolfe J. Reconsidering early parental grief following the death of a child from cancer: a new framework for future research and bereavement support. Support Care Cancer. 2020;28(9):4131-9. http://dx.doi.org/10.1007/ s00520-019-05249-3. PMid:31872296.

16. Kochen EM, Jenken F, Boelen PA, Deben LMA, Fahner JC, van den Hoogen $A$ et al. When a child dies: a systematic review of well-defined parent-focused bereavement interventions and their alignment with grief- and loss theories. BMC Palliat Care. 2020;19(1):28. http://dx.doi. org/10.1186/s12904-020-0529-z. PMid:32164668.

17. Klass D. Continuing conversation about continuing bonds. Death Stud 2006;30(9):843-58. http://dx.doi.org/10.1080/07481180600886959. PMid:17004368.

18. Fuchs T. Presence in absence: the ambiguous phenomenology of grief Phenomenol Cogn Sci. 2018;17(1):43-63. http://dx.doi.org/10.1007/ s11097-017-9506-2.

19. Costa JR, Prado E, Beal R, Wakiuchi J, Sales CA, Marcon S. S. Morte de filhos por câncer: experiências de mães enlutadas sob a ótica heideggeriana. Rev Baiana Enferm. 2019;33:e28169. http://dx.doi. org $/ 10.18471 /$ rbe.v33.28169.

20. Heidegger M. Ser e tempo. Rio de Janeiro: Vozes; 2015.

21. Paula CC, Padoin SMM, Terra MG, Souza IEO, Cabral IE. Modos de condução da entrevista em pesquisa fenomenológica: relato de experiência. Rev Bras Enferm. 2014;67(3):468-72. PMid:25054712.

22. Zveiter M, Souza IEO. Solicitude constituindo o cuidado de enfermeiras obstétricas à mulher-que-dá-à-luz-na-casa-de-parto. Esc Anna Nery. 2015;19(1):86-92.

23. Heidegger M. Seminários de Zollikon: protocolos, diálogos, cartas. 3 . ed. São Paulo: Escuta; 2017.

24. Kempfer SS, Carraro TE. Temporalidade: o existir e a perspectiva da finitude para o ser-acadêmico-de-enfermagem ao experienciar a morte. Texto Contexto Enferm. 2014;23(3):728-34. http://dx.doi. org/10.1590/0104-07072014001980013.

25. Inwood MJ. Dicionário Heidegger. Tradução de Luísa Buarque de Holanda. Rio de Janeiro: Jorge Zahar; 2002.

26. Braga TBM, Farinha MG. Heidegger: em busca de sentido para a existência humana. Rev Abordagem Gestált. 2017;23(1):65-73. http:/ dx.doi.org/10.18065/RAG.2017v23n1.7.

27. Silva JDD, Sales CA. From the imaginary to reality: the experience of bereaved parents. Rev Rene [Internet]. 2013; [citado 2003 out 17];13(5):1142-51. Disponível em: http://www.periodicos.ufc.br/rene/ article/viewFile/4124/3212

28. Freitas JL, Michel LHF. A maior dor do mundo: O luto materno em uma perspectiva fenomenológica. Psicol Estud. 2014;19(2):273-83. http:// dx.doi.org/10.1590/1413-737222324010.

29. Falkenburg JL, Van Dijk M, Tibboel D, Ganzevoort RR. The fragile spirituality of parents whose children died in the pediatric intensive care unit. J Health Care Chaplain. 2020;26(3):117-30. http://dx.doi.or g/10.1080/08854726.2019.1670538. PMid:31583971.

30. Markin RD, Zilcha-Mano S. Cultural processes in psychotherapy for perinatal loss: breaking the cultural taboo against perinatal grief Psychotherapy. 2018;55(1):20-6. http://dx.doi.org/10.1037/pst0000122. PMid:29565619.

31. Faria AF, Lerner K. Luto e medicalização: gestão do sofrimento entre mães que perderam filhos. Physis. 2019;29(3):e290317. http://dx.doi. org/10.1590/s0103-73312019290317. 
32. Rostila M, Mäki N, Martikainen P. Does the death of a child influence parental use of psychotropic medication? A follow-up register study from Finland. PLoS One. 2018;13(5):e0195500. http://dx.doi.org/10.1371/ journal.pone.0195500. PMid:29718925.

33. Spanoudis S. Apresentação, introdução, nota e epílogo. In: Heidegger $\mathrm{M}$, editor. Todos nós... ninguém: um enfoque fenomenológico do social. São Paulo: Moraes; 1981. p. 9-24.

34. Santos EM, Sales CA. Familiares enlutados: Compreensão Fenomenológica existencial de suas vivências. Texto Contexto Enferm. 2011;20(spe):214-22. http://dx.doi.org/10.1590/S010407072011000500027

35. Goldstein RD, Petty CR, Morris SE, Human M, Odendaal H, Elliott AJ et al. Transitional objects of grief. Compr Psychiatry. 2020;98:152161. http://dx.doi.org/10.1016/j.comppsych.2020.152161. PMid:31978784.
36. Beiermann M, Kalowes P, Dyo M, Mondor A. Family Members' and Intensive Care Unit Nurses' Response to the ECG Memento@ During the Bereavement Period. Dimens Crit Care Nurs. 2017;36(6):317-26. http://dx.doi.org/10.1097/DCC.0000000000000269. PMid:28976481.

37. LeDuff 3rd LD, Bradshaw WT, Blake SM. Transitional objects to faciliate grieving following perinatal loss. Adv Neonatal Care. 2017;17(5):347-53. http://dx.doi.org/10.1097/ANC.0000000000000429. PMid:28891820.

38. Kim MA, Yi J, Sang J, Jung D. A photovoice study on the bereavement experience of mothers after the death of a child. Death Stud. 2021;45(5):390404. http://dx.doi.org/10.1080/07481187.2019.1648333. PMid:31418648.

39. Foster TL, Gilmer MJ, Davies B, Dietrich MS, Barrera M, Fairclough $\mathrm{DL}$ et al. Comparison of continuing bonds reported by parents and siblings after a child's death from cancer. Death Stud. 2011;35(5):42040. http://dx.doi.org/10.1080/07481187.2011.553308. PMid:24501854.

\footnotetext{
a Artigo extraído da tese de doutorado "O vivido de mães cujos filhos morreram em decorrência de acidentes domésticos na infância", de autoria de Maria Augusta Rocha Bezerra, sob a orientação da Professora Silvana Santiago da Rocha, Programa de Pós-Graduação em Enfermagem da Universidade Federal do Piauí. Ano de defesa: 2017
} 